\title{
Editorial
}

\section{A Message to the Readers of Neuropediatrics}

\author{
Bernd Neubauer $^{1}$ Barbara Plecko ${ }^{2}$ Eugen Boltshauser ${ }^{3}$ \\ ${ }^{1}$ Department of Neuropediatrics University Children's Hospital, \\ Gießen, Germany \\ 2 Department of Neuropediatrics, University of Zurich, Zurich, \\ Switzerland \\ 3 Prof. Emeritus, Department of Neuropediatrics, University of Zurich, \\ Zurich, Switzerland
}

Neuropediatrics 2016;47:1-2.

\section{Dear Readers, Dear Colleagues,}

The year 2015 has been a busy and productive year for Neuropediatrics. The journal is thriving and growing in many different aspects.

The number of submitted articles rose from 201 (2014) to 241 (2015), corresponding to an increase of $20 \%$ in a single year.

The average turnaround time of articles from submission to the decision was significantly reduced from 40 days in 2014 to 29 days in 2015. From the editorial point of view, this resembles the most significant improvement. A cordial thank you to reviewers and the Thieme staff.

We have successfully initiated a series of review articles that are timely, and in many instances, directly at the top of the field they cover. We will try to continue this production flow over the coming year. Neuropediatrics is truly an international journal. Submissions and published articles came from 34 countries in 2014, and from 37 countries in 2015.

The impact factor of the journal increased to 1.24 (2014). This number is still in a modest order of magnitude, but has risen by $20 \%$ in 1 year. In this respect, it may be noted that the number of submitted original scientific studies is also gradually rising. We are hopeful that this tendency will continue over the coming years. The policy of our journal to ask for submissions of high scientific quality, and to allow only for case reports with outstanding scientific or clinical significance, forced us to a more critical attitude in 2015. While in 2014 only about $20 \%$ of submissions were not sent out for peer review, in 2015 this number increased to almost 30\%. After a completed review process our overall acceptance rate remained virtually unchanged at $35 \%$ in both years. Allow us a short reflection on this issue: We know that it is an extremely painful experience to receive a final rejection. This constantly happens to all of us, and the pain and disappointment it inflicts does not ameliorate with increasing age or practice in the field. However, it may be a consolation to remember that several scientific contributions, that later earned the Noble prize award, were rejected when first submitted. ${ }^{1,2}$ Amongst the pitiable were scientists such as Hans Krebs and his work on the citric acid cycle, to name just one prominent example. Therefore, it clearly remains the task of reviewers and editors to provide their criticism in a productive and helpful fashion to increase the quality of the original submission and avoid discouragement of the authors. We will again try to live up to this claim in 2016.

"Videos in Neuropediatrics" and "Images in Neuropediatrics" are two newly introduced formats that will appear over the next months. It is our plan to include one of these two in each published issue. Both are accounted for as scientific submissions and therefore are rewarded with a regular impact factor in case of publication. Formal requirements are: no abstract, word count 100 to 200 words, three images, maximum one table, and maximum five references. An informed consent letter signed by parents and children (if applicable) is a prerequisite. Please start submissions!

We thank our loyal readers and wish you all a healthy and productive 2016 !

\section{References}

1 Campanario JM. Not in our nature. Nature 1993;361:488

2 Campanario JM, Acedo E. Rejecting highly cited papers: the views of scientists who encounter resistance to their discoveries from other scientists. J Am Soc Inf Sci Tech 2007;58:734-743
Address for correspondence

Bernd Neubauer, MD,

Universitätskinderklinik,

Neuropäd, Feulgenstr. 12,

Gießen, 35392, Germany

(e-mail: Bernd.A.

Neubauer@paediat.med.

uni-giessen.de). (c) 2016 Georg Thieme Verlag KG

Stuttgart · New York
DOI http://dx.doi.org/ $10.1055 / \mathrm{s}-0035-1571260$. ISSN 0174-304X. 


\section{Thank You, Reviewers!}

Till Acker

Christopher Adamson

Stephane Auvin

Robert Avery

Luca Bartolini

Thomas Bast

Martin Benesch

Christoph Berger

Madison Berl

Genevieve Bernard

Günther Bernert

Enrico Bertini

Steffen Berweck

Rainer Blank

Eugen Boltshauser

Kees Braun

Knut Brockmann

Oliviero Bruni

Taeun Chang

Chao Cho-Ming

Giangennaro Coppola

Paolo Curatolo

Russell C. Dale

Linda de Meirleir

Linda de Vries

Richard Dodel

Olivier Dulac

Friedrich Ebinger

Zoe Englander

Harald Erhardt

David Feder

Raffaele Ferri

Martha Feucht

Hedi Folkersma

David Franz

Peter Freisinger

Tatsuya Fukasawa

Jutta Gaertner

Christian Geis

Thorsten Gerstner

Gabriele Gillessen-Kaesbach

Roger Godbout

Begoña Godes-Medrano

Corinna Grasemann

Andrea Gropman

Michael A. Grotzer

Edda Haberlandt

Annette Hackenberg

Andreas Hahn

Hans Hartmann
Martin Häusler

Ute Hehr

Gena Heidary

Florian Heinen

Raoul Hennekam

Pablo Hernaiz Driever

Kate Himmelmann

Thierry Huisman

Hans-Juergen Hupperts

Peter Huppke

Eugene Hwang

Fahmad Imtiaz

Klaus Jahn

Daniela Karall

Matthias Kieslich

Janbernd Kirschner

Katrin Klebermass-Schrehof

Joerg Klepper

Stefan Koelker

Rudolf Korinthenberg

Barbara Kornek

Eric Kossoff

Suresh Kotagal

Sanjeev V. Kothare

Ingeborg Kraegeloh-Mann

Peter Kroisel

Franco Laccone

Mirjam Landgraf

Ming Lim

Martin Lindner

John Livingston

Hanns Lochmuller

Marco Luigetti

Volker Mall

Yuji Masuda

M. Matsuo

Alexander M. McKinney

Maria F. Braga

Ute Moog

Eva Morava

Maria Mosquera

Wolfgang Mueller-Felber

Sarah B. Mulkey

Kazuhiro Muramatsu

Rima Nabbout

Lakshmi Nagarajan

Mitsuo Narita

Jun Natsume

Bernd Neubauer

Richard Newton
John R. Ostergaard

Olivier Outteryck

Robert Ouvrier

Giorgio Perilongo

Francesco Pisani

Barbara Plecko

Bwee Tien Poll-The

Andrea Poretti

Daniela Prayer

Alexander Prehn-Kristensen

Georgia Ramantani

Dietz Rating

James Reese

Veit Roessner

Elisabeth Ronne-Engstrom

Hendrik Rosewich

Andrea Rossi

Kevin Rostasy

Ulrike Schara

Marc Schlamann

Bernhard Schmitt

Markus Schmugge

Sabine Scholl-Bürgi

Andreas Sebastian Schroeder

Gul Serdaroglu

Hideaki Shiraishi

Eberhard Siebert

Stefan Spinty

Steven Stasheff

Martin Staudt

Maja Steinlin

Ulrich Stephani

Georg Stettner

Pasquale Striano

Veit Sturm

Valeria Tiranti

Regina Trollmann

Marjo van der Knaap

Adeline Vanderver

Dorothe Veraguth

Karin Walsh

Bernd Wilken

Michèl Willemsen

Nicole Wolf

Varina L.Wolf

Markus Wolff

Courtney Wusthoff

Hui Yang

Werner Zenz

Jill Zwicker 